\title{
SURVEYING CULTURAL HERITAGE: SUMMER SCHOOL FOR CONSERVATION ACTIVITIES
}

\author{
Cristiana Achille ${ }^{*}$, a, Francesco Fassi ${ }^{\text {a }}$, Alessandro Mandelli ${ }^{\text {a }}$, Fausta Fiorillo ${ }^{\text {a }}$ \\ a 3D Survey Group, Politecnico di Milano, Dept. of Architecture, Built environment and Construction \\ engineering (ABC), Italy - (cristiana.achille, francesco.fassi, alessandro.mandelli, fausta.fiorillo)@ polimi.it
}

\section{ORCID}

Cristiana Achille

Francesco Fassi

Alessandro Mandelli

Fausta Fiorillo

\author{
0000-0002-9989-853X (corresponding author - phone +39 022399 6520) \\ 0000-0001-6555-8310 \\ $0000-0001-6657-2536$ \\ 0000-0001-7046-3105
}

\section{KEYWORDS}

Cultural Heritage; Longlife learning course; Summer school; Advanced survey; Conservation, Valorisation

\section{ABSTRACT}

Since 2011, the 3DSurvey Group of Politecnico di Milano organises an annual summer school program entitled "Laboratory of Places, Ghesc and surroundings, history, survey, evolution". This activity is patronised by ICOMOS Italia and developed in collaboration with the Canova Association. This is a nonprofit organisation founded in 2001 in the medieval village of Canova (Oira di Crevoladossola, Italy) and it is an institutional member of ICOMOS (International Council on Monuments and Sites) Italy since 2010. Its primary goal is the preservation and enhancement of rural, medieval stone architecture. From 2017, the summer school is also sponsored by ISPRS society. The case study of the course is the charming, abandoned medieval village of Ghesc, located in the hamlet of Montecrestese, Domodossola (Italy). There, the Laboratory aims to create a workspace where students, freelancers, teachers and members of the association can work to the documentation of the ancient village and actively contribute to its rediscovery and conservation.

In particular, the research activity carried out in recent years by 3DSurvey Group, and Canova Association deals with all the historical and architectural artefacts in the Ossola territory, even if they don't belong to the category of monumental bounded works. The general rural architecture also includes suburban complexes made up of buildings that do not have unique architectural values by themselves but considered together represent the construction tradition of the Ossola Valley.

\section{INTRODUCTION: EDUCATION AND TRAINING PROCESS IN THE ITALIAN FRAMEWORK}

The safeguard and the valorisation of $\mathrm{CH}$ (Cultural Heritage) require professional figures owning a wide range of knowledge and skills. In Italy, schools and universities provide the base and specific training of the qualified personnel operating in this field.

The Italian Encyclopaedia Treccani (Treccani, www.treccani.it), in the last 2017 release, defines the Cultural Heritage as goods that compose the National Cultural heritage framework. It comprehends various aspects: historical, artistic, archaeological, architectural, environmental, ethnoanthropological, archival, librarian, and others that bring a historical and cultural value. The term also includes the cultural activities, which aim to build and spread cultural and artistic expressions. In Italy, "Cultural Heritage" term is used since the institution of the related Ministry (1975), replacing the former and more restrictive one "Antiquities and fine arts". Speaking about the definition of Cultural Heritage it is clear that the education path has to ensure reliable basic training about both the general contents and methods, and the specific professional masteries about Cultural Heritage. The study program has to provide not only tools for the conservation project, but also procure resources and engines for the valorisation and fruition of the data through innovative workflows (digitalising, fruition, sharing, new media, and more). 
The actual assets of the Italian University System (D.M. 509/99; D.M. 270/04) derives from a series of changing that make it more similar to the one agreed upon the other European Countries. Summarising, the current university system (Lavoro e Formazione, https://www.lavoroeformazione.it) aims to: i) shorten the times to obtain the degree, ii) reduce the dissertations, iii) organise the cultural- methodological competences with a professional training, iv) incentivise and simplify the national and international students' mobility, v) arrange a system hosted on two level of degree. Currently, the university courses provide a " 3 years +2 years" formula, in other words, a first and second level degree (Fig. 1).

The first level degree lasts three years and intends to ensure to the student an adequate competence about the scientific methods and contents in general, plus the acquisition of specific professional knowledge. After the three-year period, gained $180 \mathrm{CFU}$ (University Formative Credits), the students are ready to enter in the labour market or to attend first-level masters (at least earning $60 \mathrm{CFU}$ ) and post-graduate schools. Otherwise, with the second level degree, organised in two years, the scholars receive advanced training for high qualification activities in specific fields (the student will collect, at the end of his path, $180 \mathrm{cfu}+120 \mathrm{cfu}=$ $300 \mathrm{cfu}$ ). After the master degree, it is possible to continue the studies choosing among second level masters, $\mathrm{PhD}$ courses ( 3 years) or advanced post-graduate schools. Probably, the main innovation introduced by the university reform is the organisation of the path through a system based on the university formative credits (CFU); they measure the overall working load of the student (lessons, individual study, seminars, laboratories, and more). Each exam corresponds to some credits that identify the more or less lofty formative goal reached. Every year, on average, the student can dedicate to the university studies some hours that correspond to 60 credits. The study program offers key activities, organised in monographic courses or integrated laboratories, according to the lists that define the degree classes' features and the directives of each university.

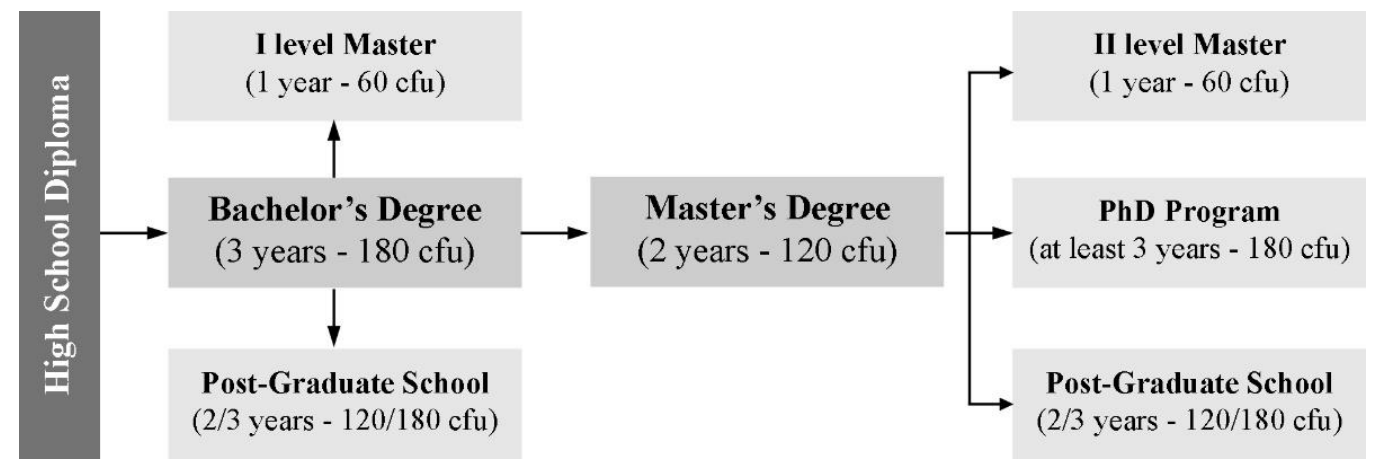

Fig. 1 The Italian University System. Source: Lavoro e Formazione, www.lavoroeformazione.it.

In Italy, there are 79 universities (CeStOr, www.cestor.it), to which corresponds a high number of degree classes, in all the disciplines. Among these categories, the bachelor's that deal with Cultural Heritage (MIUR, www.miur.it) are the Class L01 Degree in Cultural Heritage and Class L43 Degree in Technologies for the Conservation and Restoration of Cultural Heritage. On the other hand, speaking about the master degree, the classes are: Class LM10 Master Degree in Conservation of Architectural and Environmental Heritage, Class LM11 Master Degree in Conservation and Restoration of Cultural Heritage, Class LM45 Master Degree in Museology and Cultural Heritage. In the alternative, the University of the study of Turin proposes a single cycle Master Degree LMR/02, in agreement with Fondazione Centro Conservazione e Restauro dei Beni Culturali "La Venaria Reale" (Suscor, www.conservazionerestauro.campusnet.unito.it; Venaria Reale, www.centrorestaurovenaria.it). Also in Florence, the Scuola di Alta Formazione e di Studio releases a diploma that has the same value of a single cycle master degree diploma in Conservation and Restoration of Cultural Heritage, LMR/02 (Opificio delle Pietre Dure, www.opificiodellepietredure.it).

The target of these degree programs is to answer to the national and international need of professional figures that operate in a modern perspective for the safeguard, the conservation and the valorisation of Cultural Heritage (AIB, www.aib.it). The graduate professionals in this field can work inside the restoration laboratories and companies, the Ministry of Cultural Heritage and Activities appointed to the safeguard of Cultural Heritage (government supervision departments, museums, libraries, archives, and more), the professional associations of the field, the public and private Institution and Research Authorities. Alternatively, who wants to deepen his knowledge or increase his specialisation level after the graduation, can consider attending other study paths, as master, $\mathrm{PhD}$ programs, post-graduate schools, and training courses. 
Masters are post-graduated bachelor's courses (first level masters) or post-graduate master courses (second level master), organised in partnership with other public or private institutions or companies, to give the students a scientific improvement and high training. They offer professional, technical-operative or design skills. The admission is close to a restricted number of participants, as long as the guide of teachers and tutor is guaranteed. To complete the master, it is necessary also to conclude an internship among companies or institutions (Master Programs websites).

On the other hand, the $\mathrm{PhD}$ program lasts three years, and it is possible to attend it after the master degree. Its target is to give the theoretical and practical knowledge, necessary for the research activities. At the end of the path, the candidate has to produce an elaboration summarising the results of their operations ( $\mathrm{PhD}$ programs websites). The $\mathrm{PhD}$ courses about Cultural Heritage has to provide a wide range of knowledge and skills, through a multidisciplinary approach, where to combine the traditional humanistic disciplines and the scientific ones. The paths are different but integrated, where each field (architecture, archaeology, survey, maintenance, conservation, history, multimedia, and more) presents its specificities as the theory, the methodologies and the survey tools available.

Another possibility is to attend the advanced post-graduate schools (SIRA, www.sirarestauroarchitettonico.it). The Post-Graduate School of Architectural and Environmental Heritage (Italian acronym S.S.B.A.P.) trains high profile specialists for the study, safeguard, restoration, maintenance, and valorisation of the architectural and environmental heritage. The aim is to give a specific critical-historical, technical and professional competence integrating the university skills, and to provide a more extensive knowledge of the methods and operational techniques for the management of the cultural patrimony. The S.S.B.A.P. in Italy are inside: Politecnico di Bari, Università degli Studi di Firenze, Università degli studi di Genova, Politecnico di Milano, Università degli Studi Federico II di Napoli, Università di roma 'La Sapienza', Politecnico di Torino, IUAV Università di Venezia.

There are also other training opportunities, as the "lifelong learning courses", which comprehend formative activities for employed or non-employed people, which need a professional-technical or cultural upgrade. All the citizens of every age, culture and professional or social condition can attend lifelong learning courses. The target is to ease the learning, growing, and the training of professional and cultural capacity useful for their entire lifecycle. In fact, the term is not only referred to employment goals, but also to personal, social, and civic ones (Lifelong Learning websites).

As explained so far, the proposal for the training in the Cultural Heritage field in Italy is vast and varied, confirming the growing necessity of professionals operating on the built heritage. To testify this statement, the latest ICOMOS recommendations (ICOMOS 2017) contain a series of proposals:

i. planning, promoting, and strengthen the collaboration with the Public Research Institutions, Universities, Post-Graduate schools, The Schools and Institute of each order and grade. In this way, it is possible to guarantee the introduction, of the knowledge and tests of the vulnerability and risks, associated with the integrated conservation of Cultural Heritage, promoting the "prevention culture";

ii. planning and realising training/information actions, collaborating with other Entities, firstly ICCROM and Professional Orders;

iii. collaborating with the Entities predisposed to identify new professional figures;

iv. promoting fundraising and participating in an innovative research project about the safeguard of Cultural Heritage.

Even the permanent Observatory on Learning and Training - Europe 2020 (ISFOL, www.isfol.it), based on the recommendations of Agenda 2020, underlines the centrality of the activities and education paths that the European Union's Countries will be able to launch. All the citizens should be able to reach a higher level of instruction and training than the actual ones, being involved in professionalising and formative paths.

In this framework, the European countries take care of the accessibility of the population to the educational activities among the entire life cycle, to the phenomena connected to the lack of participation of specific target to working and training paths, to innovative modalities of knowledge dissemination through both the working environment and less structured learning context.

The relevance of the topic "training and cultural heritage" is evident. The interest of the scientific community confirms the necessity to organise study paths better structured, towards theoretical and practical learning. The project "Laboratory of Places", combined between Politecnico di Milano and Canova Association, moves in this direction. It is a lifelong learning course (4 CFU), aimed at those who want to deal with the knowledge survey of Cultural Heritage. In this way it is guaranteed training and professional 
updating to students, graduates, administrators, public functionaries, and professionals, completing the formative offer of the University.

\section{LABORATORY OF PLACES - GHESC AND SURROUNDINGS - HISTORY, SURVEY, EVOLUTION}

\subsection{The partnership with the "Canova Association"}

The summer school "Laboratory of Places 2017 - Ghesc and surroundings - History, survey, evolution" is organised by the 3D Survey Group (ABC Department of Politecnico di Milano) and Canova Association. The school offers different activities that integrate the university teaching and concurs to the training of professional roles operating in the safeguard, conservation and valorisation of $\mathrm{CH}$. The Summer School is international because of the strong need for training in this sector both in Italy and abroad.

The coordinators considered mandatory to organise the course in close cooperation with Canova Association, referring to the ICOMOS suggestions (ICOMOS 2017). Canova Association resides on the territory and promotes a shared knowledge supporting local projects. "Canova Association is an international non-profit organisation founded in 2001 in the medieval village of Canova, Oira di Crevoladossola, Italy. Canova is an institutional member of ICOMOS Italy since 2010. The principal goal of the Canova Association is the preservation and enhancement of rural medieval stone architecture. Canova Association presents a rich program of events each year, some reserved for members only but the majority open to the public. These occasions are meant to increase the involvement of people dedicated to the continuation and protection of European and our local heritage of ancient rural stone architecture. Art and architecture intertwine, stimulating research and debate, revolving around the conviction that old stone construction can offer adequate if not superior models in our search today for sustainable human dwelling solutions. The continuing insensitivity to this fact is resulting in indiscriminate demolition and renovation, forever cancelling the precious heritage of rural stone architecture in Italy and Europe. The intention and goal of the Canova Association are to reverse this tendency, carrying out activities aimed at sensitising both the public and private sector. For over ten years the Canova Association organises fields school regarding the theme of architectural restoration in collaboration with Italian and foreign universities. The participants followed by a master builder, have the opportunity to know and learn the techniques of typical Ossola architecture from the best perspective, the one that sees them engaged directly. In recent years, the field schools take place in the suggestive medieval abandoned village of Ghesc. It is a village across the river from Canova. Large trees grew up are living within the walls of the houses, and the place exudes a charming air of mystery. Ghesc is the ideal stage for what we like to call the "Infinite Laboratory", and is the playing field of the International Canova Field School program" (Canova Association, www.canovacanova.com; Achille et al., 2017). The cooperation between university and Canova Association is fundamental as they both consider $\mathrm{CH}$ not only as archaeological, architectonical, artistic and archival heritages but as a whole of assets including oral, practical and local traditions. $\mathrm{CH}$ represents a shared resource, and their conservation and valorisation are possible only respecting local cultures. The collaboration with the "living" Canova Association permits to know and appreciate how to sustainably intervene (times and modalities) in the Ossolano territory.

Cultural Heritage Code has widened the meaning of "Cultural Heritage" not only regarding the chronology but also considering the goods types (tangible and intangible). For this reason, it is necessary to prepare new scientific and professional competences, which can handle the knowledge, the safeguard and the valorisation through multidisciplinary paths. Thus, the Summer School "Laboratory of Places" offers a training project aimed to deepen geometric survey, conservation, and valorisation. The course forms scholars and professionals able to deal with methodological and practical issues with a critical approach and research capabilities applying national and international standards.

The Summer School guarantees the achievement of a series of targets. The first one is the learning of the primary disciplines and methods linked to the analysis of $\mathrm{CH}$, such as geometric survey, materials identifications and more. The second aim of the School is the attainment of capabilities obtained through the practical exercise on the field. This methodology lets to become familiar with the full range of topographical and photogrammetric instruments and with the best practices applied on $\mathrm{CH}$. Moreover, the tight collaboration with the Canova Association combines the "local knowledge" and "traditional approach" with the most innovative data elaboration, and fruition tools (web/GIS, new media, digital repositories, information systems, and others). In this way, it integrates necessary competencies and helps the development of professional skills operating in safeguard, conservation and valorisation. In fact, standard 
and advanced knowledge, understandings, and awareness of environment are fundamental to deal with $\mathrm{CH}$ projects. The participants face the problems with a multidisciplinary approach independently. For this reason, it is necessary to apply their competencies to intervene correctly. Working on a real case study lets to test what has been learned and verify the reachability of the settled targets.

\subsection{Long-life learning course: activities and aims}

The activities of the Summer School take place in Ghesc. "Ghesc is a small medieval village, uninhabited for more than one hundred years. The encroaching forest has gradually embraced its buildings and terraces, creating a highly evocative and fascinating environment. Hidden between the Swiss alpine border and the narrow Ossola Valley, Ghesc is located in the municipality of Montecrestese. Thanks to its relative isolation, the Ossola Valley has kept its secrets well hidden. It is an area of extraordinary natural beauty with an abundance of undiscovered stone villages. Ghesc is essentially composed of seven houses, only one of which still conserves its original stone roof, and the rest are in varying states of neglect. The village's equipment also counts a bread oven and a watermill for grinding flour, both of which are existing but non-functional. An analysis of the surrounding landscape illustrates nature's steady march in reclaiming its original territory. The time and the weather conditions seriously compromised the retaining stone walls of the stream, and the terracing once cultivated with vineyards, rye and hay are now home to chestnut and beech forest. Historical documents referring to Ghesc are rare but those that do exist apparently demonstrate its ancient origins. A document dating back to 1411 attests to the payment of tithes owed to the Municipality of Montecrestese, referring to the then-current name of Gexo. Both the Teresian cadastral maps of 1722 and the Rabbini Maps of 1863 identify the area in more recent times. The surroundings of the village of Ghesc is particularly rich in historical and architectural sites. Many terraces, relatively well conserved, encircle the nucleus of houses. In the little valley below the village, there is a mill house built for grinding rye as well as two lime kilns for the production of lime mortar, a fundamental material in the traditional building trade. The presence also of an ancient tomblike enclosure built in the terracing and a "balma" (a large room created by excavating beneath a giant boulder), as well as the Celtic site of Castelluccio a short distance away, is testimony to the area's long history of human habitation" (Achille et al. 2017; Quaderni di Ghesc 2010).

The Summer School is organized into four parts:

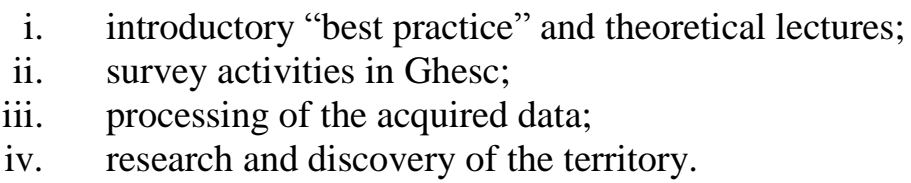

The maximum number of participants is 12 , and to attend it is mandatory to send a CV with a motivation letter. The VI edition of the Summer School took place from the $26^{\text {th }}$ July to the $4^{\text {th }}$ August 2017 . Over the years the participants were: university students (architecture, engineering, history, and more); professionals (surveyors, architects, archaeologists, photographers, public employees); employees of university institutes. A heterogeneous group of scientists that, for various reasons, work or will work in $\mathrm{CH}$ field.

The different geographical and cultural origins, the different ages, competencies, and personal experiences make the team activities interdisciplinary and help to understand various approaching methods towards $\mathrm{CH}$. A common language becomes obligatory to work together as a team. The summer school aims to enable students to know how to use tools and methods after proper theoretical preparation, and then to be able to process the collected data critically.

The main scopes of the course are as follows (Achille et al. 2017):

i. encourage the learning of modern and innovative survey methods: Topographic instruments survey and data processing. Laser scanner tools - acquisition and management point clouds, elaboration of plans, sections, profiles, 3D models. Photogrammetric survey - digital camera, UAV, on-site calibration, image matching, orthophoto, 3D model; Structured light scanner survey of small object, mesh processing, 3D model);

ii. promote the learning of methods to investigate and recognise materials (material survey, study the state of decay, cataloguing, the collection of samples, analysis);

iii. build capacity for the 'virtual design' of interventions based on the collected data (develop hypotheses project from plans, sections, and 3D models); 
iv. promote the dissemination of user-friendly and low-cost technologies: the broadest diffusion of the necessary tools for documenting, conserving and monitoring of cultural heritage. Encouraging the use of new tools and techniques so that they support the various phases of the conservation process; tools as means and not as the ends; enhance the use of digital technologies to promote the site, even from the touristic point of view. Processing the data while keeping in mind its future potential employment, not only for the necessary conservation work but also for the dissemination via web at various user levels. Creating 3D models and movies viewable/accessible through the internet;

v. develop data-sharing procedures with online platforms to provide and ensure access to useful information for conservation practices (share platforms and tools for the dissemination of knowledge acquired). Through the use of shared platforms one can aspire to bridge the technologic gap between experts-technologists and conservatives, between managers and end users of data and information;

vi. promote knowledge of the territory and its peculiarities by offering students lectures on the history of the Ossola Valley as well as guided tours to places of interest, thus gaining a broad and coherent awareness of the local culture. The summer school also represents an opportunity for revitalisation and rediscovery of forgotten places;

vii. actively contribute to the conservation process through the dissemination of best practices through ongoing dialogue between scientific and local communities, to avoid duplication of effort; help establish guidelines that ensure the compliance of conservation practices;

viii. the disciplines of geomatics and restoration by their nature require teamwork. It is, therefore, necessary to learn to work together, encouraging multidisciplinary cooperation and dynamic inter-change among the summer school participants.

\subsubsection{Learning of modern and innovative survey methods}

The survey methods include observation, measurements and critical analysis of the built heritage. Compared to the traditional survey methods adopted in the $\mathrm{CH}$ field, the modern survey instruments allow getting complete, and adequate data in a relatively short time.

Nowadays, the difficulties do not reside in using the survey tools, but in the data elaboration. A good survey needs theoretical and practical skills that can be obtained only through the study and the experience directly on the field. During the Summer School, the participants spend most of the time using topographic and photogrammetric instruments. They have to plan and accomplish a survey after attending some necessary theoretical lectures.

The techniques adopted and the subsequent elaborations are different according to the final purpose. The methodologies depend on the restitution scale (details), the characteristics of the investigated object (dimensions, shape, position, materials), and the surrounding environment. It is possible to join different methodologies and instruments and use them simultaneously to achieve a final "hybrid" product, which meets the set requirements. Moreover, the combination of various techniques permits to optimise the acquisition and elaboration stage taking advantage of the best characteristics and performances of each instrument (Remondino 2011).

Through the years, the summer school also used tethered balloons (2012) and UAV (from 2013 to 2017) for the aerial survey, until the latest edition (2017) where the scholars had the chance to employ the most modern laser scanner technologies, as the Leica portable scanners BLK 360 and Pegasus Backpack (Fig. 2).
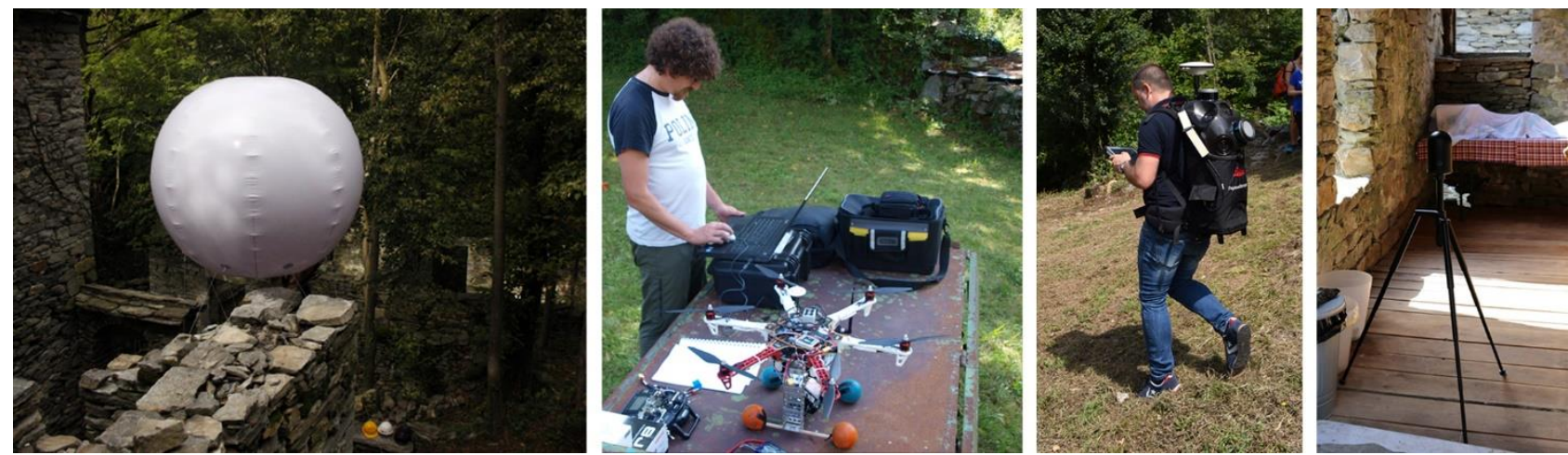
Fig. 2 Starting from the left: i) tethered balloon; ii) UAV; iii) Leica Pegasus Backpack; iv) Leica BLK360

For the didactic purposes, the tutors design the survey to allow each participant to use and compare all the different survey techniques and instruments. The campaign contemplates a topographic network to support all the following laser scanner and photogrammetric, both close range and UAV activities. The students elaborate the data (Fig. 3) to produce three-dimensional models and classical bi-dimensional drawings (plans, prospects, and sections). Usually, the representation scale settled is 1:50 that is the "minimum" required in the architectonical field. However, where is necessary, it is possible to use multi-scalar representations, integrating some specific details at a bigger scale. The choice of scale ratio depends on the following criteria: correct hierarchy of information, legibility, measurability of the elements and clarity in the detail's description.
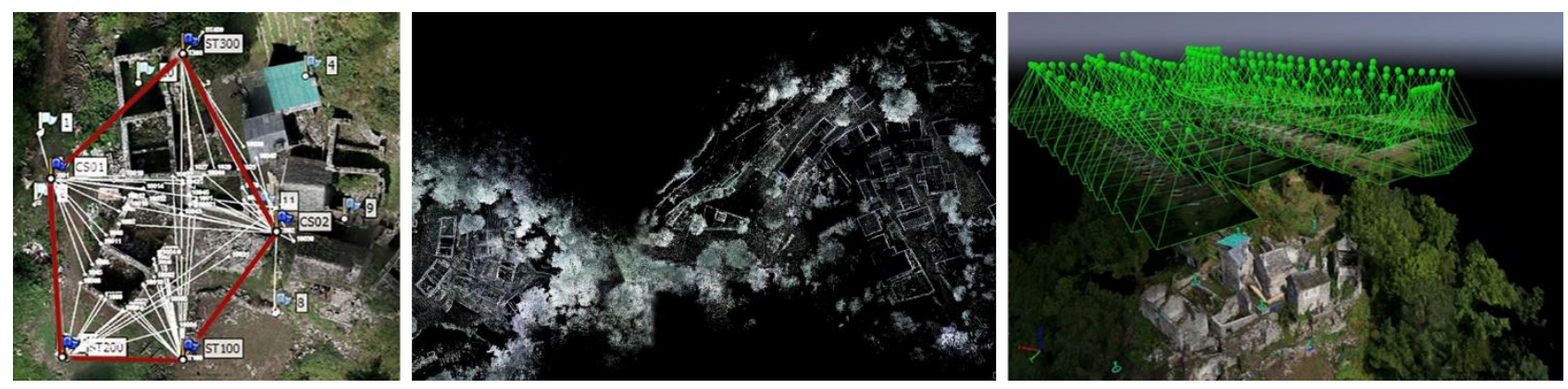

Fig. 3 The image shows some of the rough data concerning (from the left): i) the topographic campaign; ii) Leica Pegasus Backpack; iii) aerial photogrammetric survey

It is clear that a ten-days course does not let to acquire an in-depth knowledge regarding the survey tools, but this is not the scope. The aim is to inform about the existence of these methodologies, highlighting the positive aspects and the limits, and focalizing the attention on metrological fundamentals that, nowadays, are often disregarded blindly trusting the automatisms and the greater ease of use of the instruments. In this way, the operators of $\mathrm{CH}$ field will be able to decide if and when a type of instrument is necessary, considering the expected results, the time, and the available budget. Knowing the possible means and their kind of products permits a better communication between different professionals that have to operate on Cultural Heritage.

\subsubsection{Learning of methods to investigate and recognise materials}

It is necessary to have at disposal not only geometrical data but also information about the material's consistency, to arrange an adequate conservation project. Once the attendants complete the survey and the restitution (bi-dimensional drawings in DWG format and orthophotos at 1:50 scale) of the architectural shapes, they proceed with the analysis of the materials. This kind of investigation and the consequent decay's one, represent the first phase of the studies needed to obtain an overall knowledge of the features and conservation state of a building. This step uses the macroscopic observation, made with the naked eye, of the visible architectural surface. At the end of this survey, it is possible to proceed with the instrumental inquiries, even invasive, and samples where it is necessary (Lombardini et al. 2011). At this stage, it is essential to take care of the communication's modalities; in particular, the graphics restitution has to transmit the information making them crystal clear to anyone has to operate in the next project phases.

For this reason, the students have to represent the identification of the materials, the decay analysis, and the methodology of interventions with opportune graphics symbols (Fig. 4). In Italy, the NorMaL commission (NorMaL - Normativa Manufatti Lapidei) wrote the NorMaL language former $1 / 88$, today UNI 1182. This code regards the decay representation of the surfaces, allowing the description of stones materials' alterations and the degradations. The norm views both the natural (rocks) and artificial (mortar, plaster, ceramics) stones. In this way, it answers to the need to adopt standardised and repeatable methods to guarantee the comparison between results. The progressive spread of this NorMaL language brings to the production of elaborations that referred to the same vocabulary. 


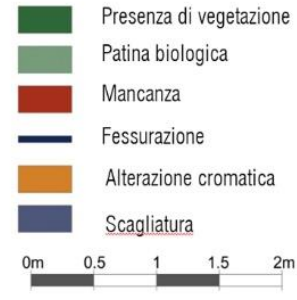

Fig. 4 Example of a decay analysis drawing

Another reference "dictionary" is the one by ISCS (ISCS - International Scientific Committee for Stone) of ICOMOS. "In studies on stone deterioration and conservation, terminological confusions lead to major communication problems between scientists, conservators and practitioners. In this context, it is of primary importance to set up a common language; if degradation patterns can be shown, named and described, then they can be recognised and compared with similar ones in a more accurate way in further investigations. The ISCS glossary constitutes an important tool for scientific discussions on decay phenomena and processes. It is also an excellent basis for tutorials on stone deterioration. It is based on the careful examination of preexisting glossaries of English terms. It does not aim at replacing these glossaries, often set up originally in a language other than English, and for most of them done to a high standard (ICOMOS-ISCS 2008)". Also, in this case, the target is to learn a workflow and be aware of the reference regulations. It is essential to comprehend how to handle the knowledge acquired during the course to participate to the planning and evaluating of the safeguard and maintenance interventions of Cultural Heritage, with critical spirit and availability to interdisciplinary teamwork. This experience will help the professional to work in also different landscape by the Ossolano's, replaying a working pipeline based on the study, the comparison, and the critical analysis of the data, starting from the national and international rules.

\subsubsection{Virtual design of interventions: 3D modelling}

The survey technologies satisfy the documentation requirements of Cultural Heritage and open new research scenery, starting from a geometrically correct and complete database, usable in sectors until now separated, such as - for example - project simulation of conservation and reuse interventions.

The accurate and georeferenced geometric survey ensures the correlation of all the analysis conducted and constitutes the indispensable basis for any project. The redundancy of the data produced by surveying instruments (laser scanners or digital cameras) eliminates the phase of information selection during acquisition and allows the production of models with different characteristics, for different needs.

Therefore, the survey activities and the subsequent representation phase are connected to the questions about the interpretation of the phenomena observed on the existing building and their representation on the 3D models.

Today many software offer exciting solutions for the three-dimensional modelling both for the building of the assumptions about the history of the investigated object, both as regards the project hypotheses. Visual communication is the most common use of $3 \mathrm{D}$ digital models in the context of Cultural Heritage. The dissemination happens through both passive video (such as animations, which do not provide for the intervention of the user) or active type (such as installations interactive multimedia or virtual navigation systems, which require user intervention).

In the case study of Ghesc, the objective of virtual reconstructions is to give a measure to the hypotheses about the original structure of the buildings and to make simulations on possible conservation/reconstruction interventions (Fig. 5, Fig. 6). The students can hypothesise the original consistency of the buildings of the village, starting from the collected data (geometric data, historical sources, observations and analysis produced on the materials, and more (Fassi et al 2016. 

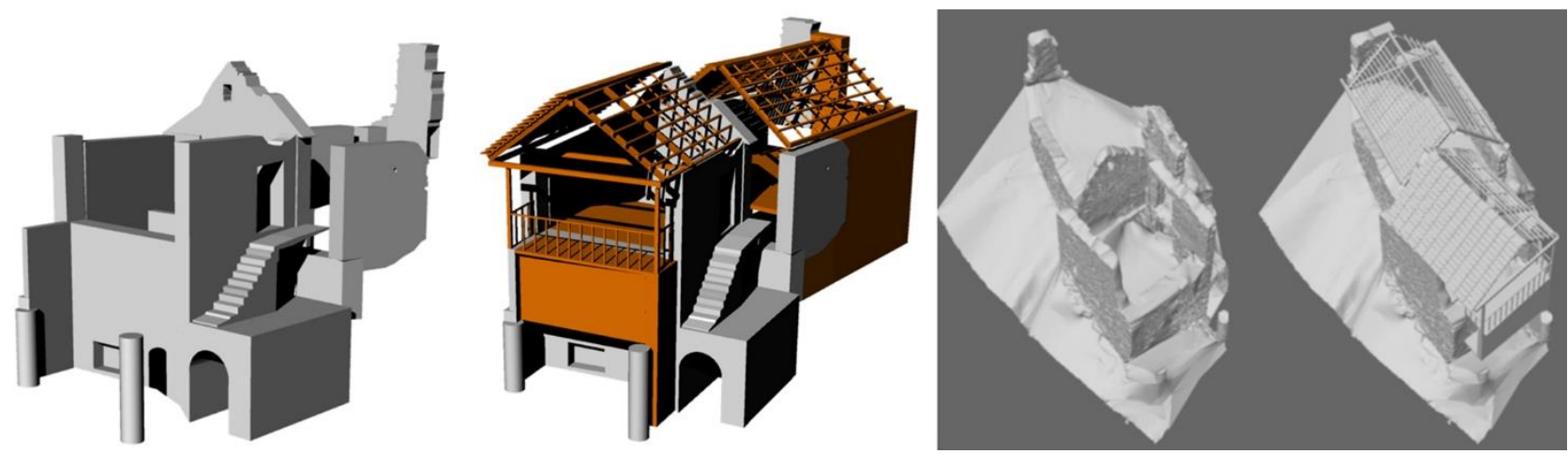

Fig. 5 Hypothesis on the original shape of the "column building" in Ghesc: 3D modelling from survey data (software used: Rhinoceros 5.0, SketchUp 2015)
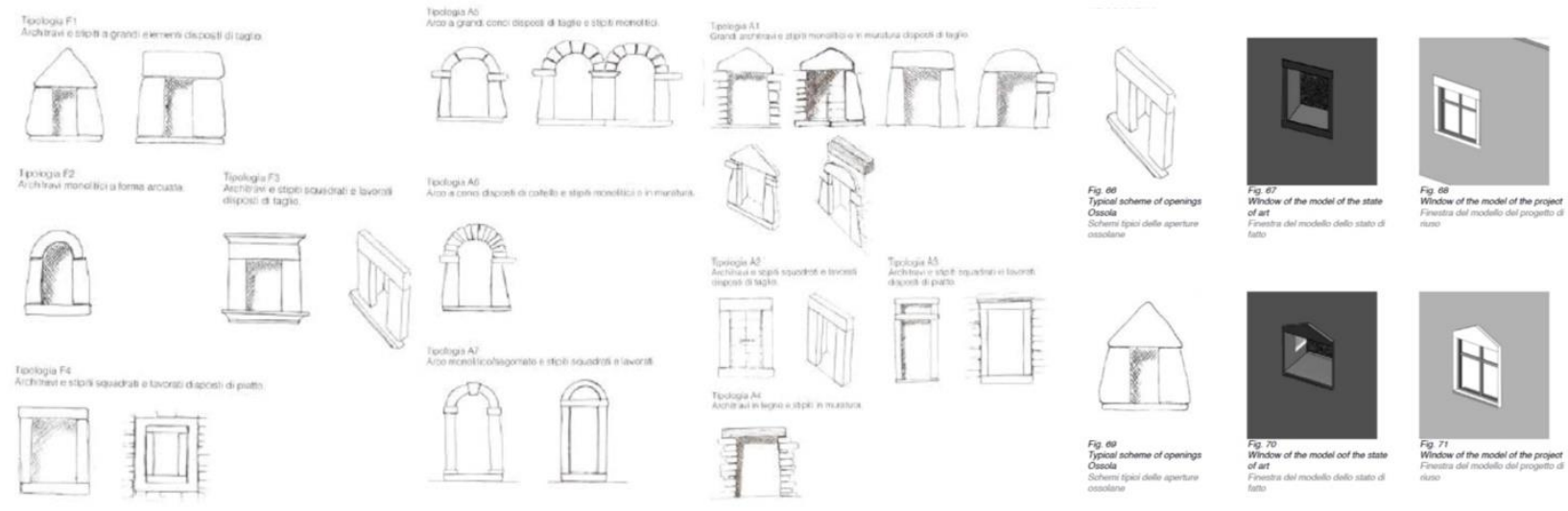

Fig. 6 Study of the typical scheme of openings in Ossola buildings; freehand sketches and 3D modelling from survey data (software used: Revit 2013)

During the course, the tutors introduce the methodologies of 3D modelling (direct and parametric), including the BIM approach. Today the use of BIM processes (Fig. 7) is spreading also for projects involving the existing building, so it is necessary to present this theme. Compared to traditional methods the creation of models according to the BIM logic becomes interesting for the study of the sequence of works required for the conservation and reuse project. Hypotheses and evaluations can be made that take into account both time and costs.
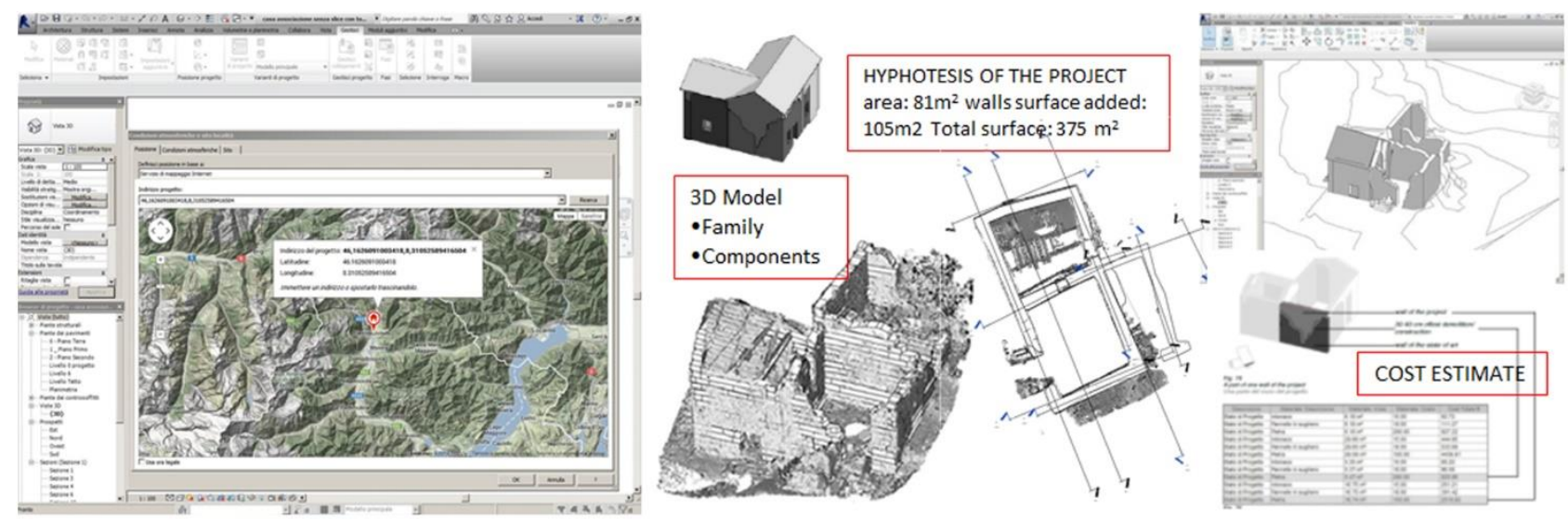

Fig. 7 Uploading of the geographic coordinates of Ghesc; model of the case study starting from a point cloud using the "InPlace Family" in Revit 2013. Source: Corda, S., Bim\&Heritage Hypothesis regarding the re-use project of a rural village, Politecnico di Milano Degree Program in Architecture, Academic Year 2013-2014 
Furthermore, three-dimensional virtual models offer new opportunities in communication, diffusion and training. In fact, these models allow the users to communicate effectively, quickly, and "repeatable"

\subsubsection{Promoting the dissemination of user-friendly and low-cost technologies, enhancing the use of digital techniques}

Modern digitalisation techniques, shared data platforms, three-dimensional simulation/prediction/ reconstruction practices, the design of friendly interfaces for data access, offer new ways of using and transmitting knowledge. In general, the production of 3D digital models (Fig. 8) is useful in many areas (from the most diffuse documentation to the conservation and restoration, teaching activities, research project, and more) but, it is necessary to establish before what is the goal that the model must respond to ensure the proper results. The choice of objectives is vital for the subsequent study and interpretation processes that can be implemented on three-dimensional models.

Among the possible uses of digital models, there is the possibility of making high fidelity copies of original objects. Today there are several sensors (in particular scanners) and tools that allow you to acquire the shape of small and medium-sized objects with high accuracy. The use of these devices, some of which low cost, leads to the production of digital models that are nothing but accurate copies of the scanned objects. In the world of Cultural Heritage these replicas can be used to exhibit an object (if the original is not available); to permanently or temporarily replace original works; for the construction of educational paths for blind people; for merchandising activities and more.
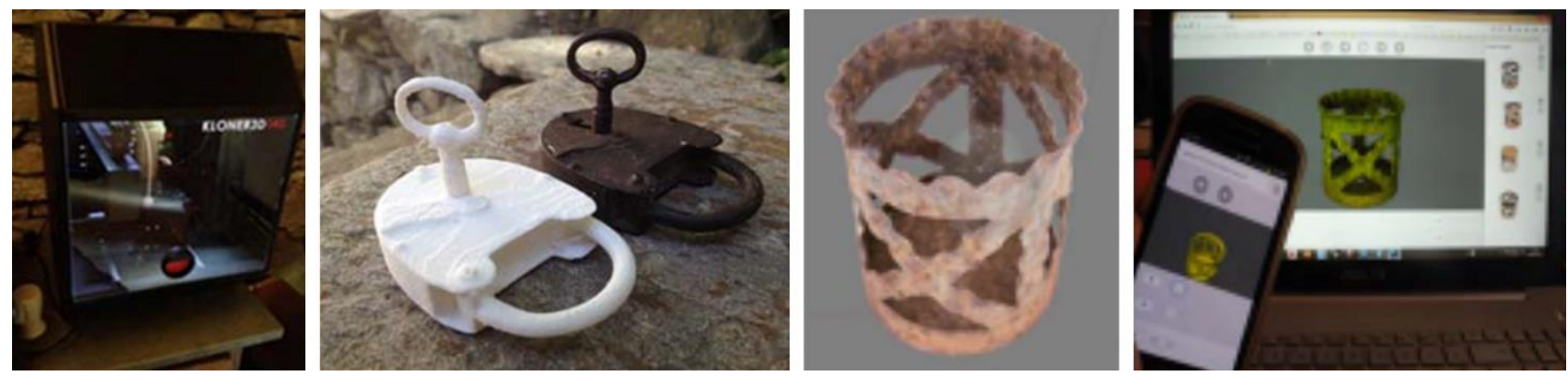

Fig. 8 Starting from the left: i) 3d printing of photogrammetric models; ii) the real object and its printed copy; iii) and iv) sharing high resolution $3 \mathrm{~d}$ models of small objects in an on-line visualisation system (BIM3DSG)

Another application concerns the possibility of contributing to restoration. Thanks to 3D printing technologies it is possible to design and reproduce the missing parts of a work, to offer the public a more useful explanation of the original structure of the object.

During the summer school in Ghesc, in collaboration with the Rosminiano Museum of Domodossola, the participants surveyed some objects preserved in the Museum. The goal of the activity was to create digital models to physically replicate them through 3D printing. The 3D survey and printing technologies offer exciting opportunities to museums and cultural institutions to enhance the visibility of their collections. In addition to the use of 3D copies in the integrative restoration or tactile set-up, 3D models can be used to create three-dimensional digital archives of artefacts for dissemination purposes to develop online museums or virtual reality tourist applications.

\subsubsection{Developing of data-sharing procedures}

At the end of the survey activities (geometric, material, historical, and others), the problem is the management of different data (texts, historical documents, images, 2D representations, 3D models, numerical data, and more). It is necessary (or better indispensable) to make the data accessible to the restoration managers in an integrated environment to guarantee complete access to the analyses and thus allow the control of the activities in progress; comparing the object before restoration with all kind of interventions used in the field/implemented (Fig. 9). Most of the collected data refer to different spatial locations on the 
building, and digital 3D models can be the ideal means of viewing, storing and correlating all this information. A great deal of time is devoted to the sharing of data collected through online platforms to
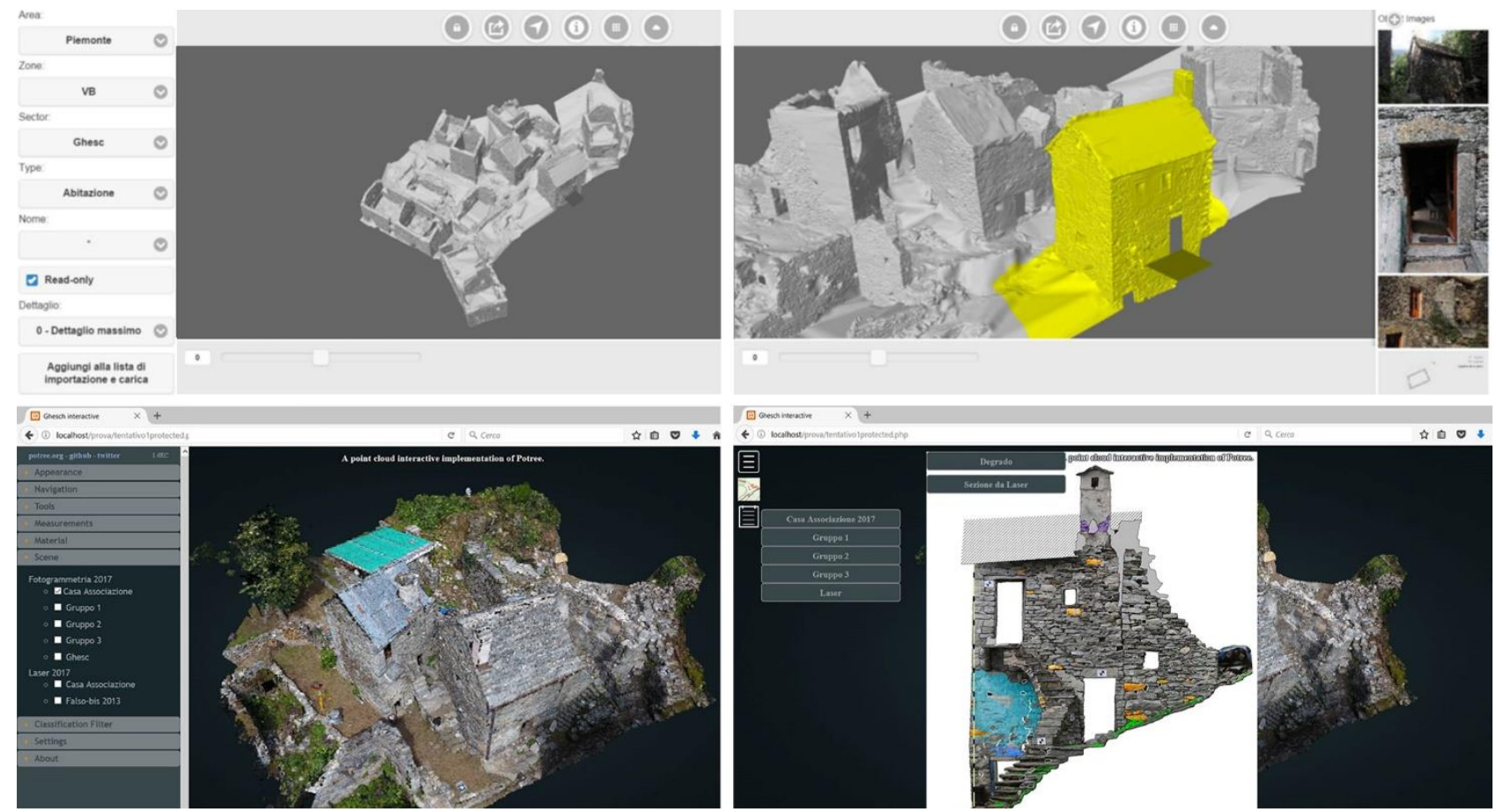

Fig. 9 The informative system BIM3DSG used to visualize, collect, and share surveyed data, 3d models, images, information

It is essential to consolidate the use of share platforms and tools for the dissemination of knowledge to overcome cultural inequalities and make information genuinely accessible.

The summer school aims to give priority to the use of so-called user-friendly and low-cost technologies to ensure the spreading of the tools specially created for documentation, conservation and monitoring of cultural heritage (Fig. 10). The promotion of online tools and platforms' development democratically provides access for referencing standards and procedures in the practice of preservation of Cultural Heritage (ICOMOS 2014).
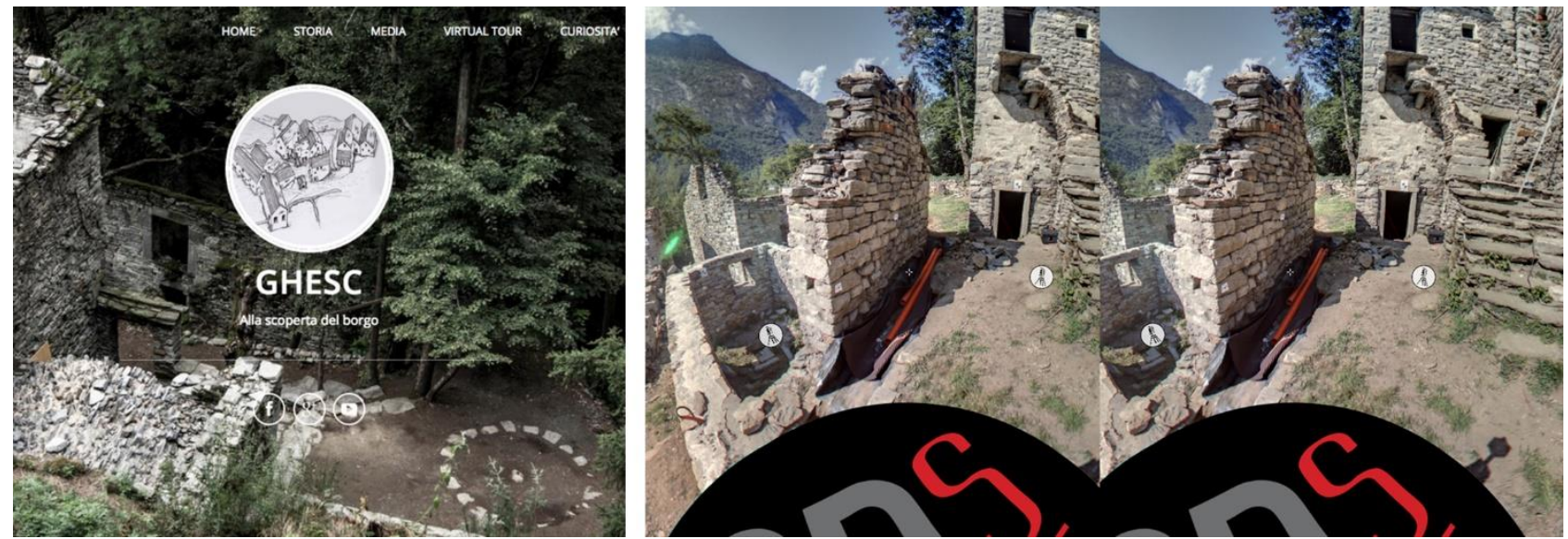

Fig. 10 A proposal for a website page and an on-line 3d virtual tour of Ghesc village

\subsubsection{Promoting the territory's knowledge}

The summer school is also an occasion for revitalising and rediscovering forgotten places. During their stay in Ghesc, students take part in lessons and guided tours in Ossola territory (Fig.11), thus gaining a broad 
and coherent vision of local culture. The "heritage sites" (sites, landscapes) can take different values for multiple communities associated with them, and the process of value identifying must take into account each group. It is necessary to set up separate levels of cooperation networks among the various stakeholders, to take on heritage issues and create new value sequence through innovative synergies, employ dynamic and adaptable processes of involvement. The assets of the long-term social impacts of heritage conservation planned interventions helps to recognise the link between communities and their heritage; respecting the right of local communities to identify the values and knowledge systems contained in their culture.

It is necessary to reactivate a development on a "human scale", as a basis for bottom-up creative approaches and to create a link between heritage conservation and local and sustainable economic development (ICOMOS 2014). In this sense, the summer school actively contributes to the discovery of the Ossolan territory through guided tours organised by the Canova Association. For this reason, the close-knit relationship between the University and the Canova Association is strategic; the "education-training" on the themes of the landscape, the environment and cultural heritage is useful when you know what you want to protect and enhance.
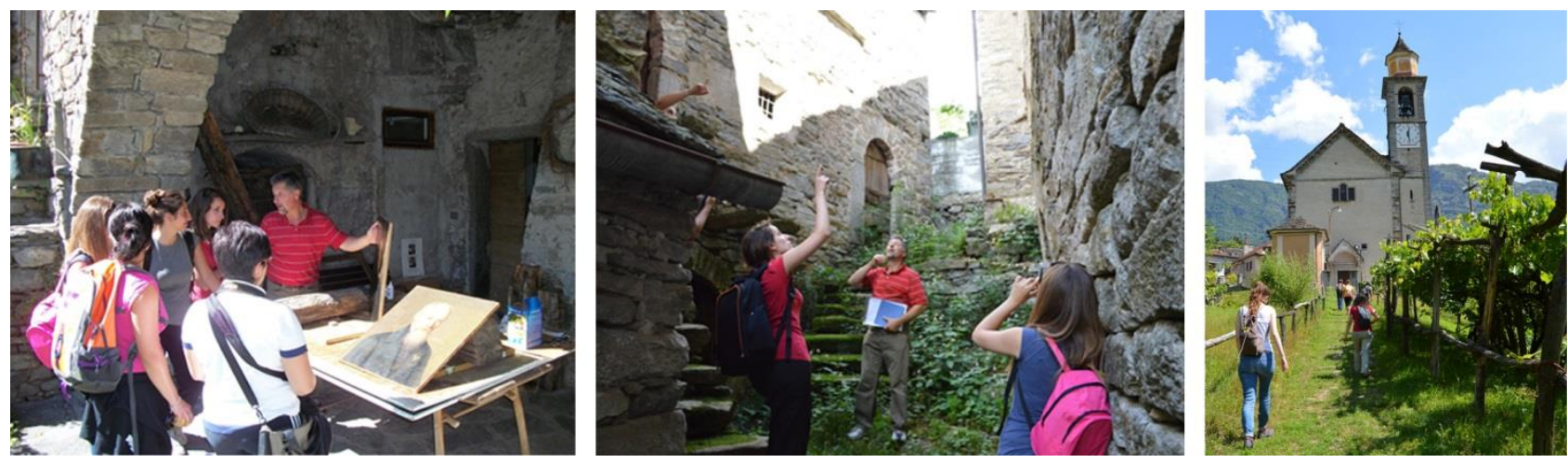

Fig. 11 Guided tours in Ossola territory

\subsubsection{Actively best practices}

From the world of work, the need for interdisciplinary training to complexity or, better, the attitude to multidisciplinary work come to light more frequently.

The educational and training path cannot exclude the understanding of the interlocutors as well as the context in which they live, they move and develop experiences and relationships.

It follows that any education and training offer cannot be repeated immutably and everywhere: it is necessary to give a methodological and theoretical system, referring to the context, to the necessity and demands encountered for carrying out of the educational and training activities.

In the framework of coherent and coordinated planning aimed at conservation, the professional must be able to analyse the data (constitutive materials, construction technique, state of preservation); plan and direct the interventions; coordinate the other operators performing complementary activities.

Promoting "best practices" means: i) developing guidelines for interdisciplinary research in order to bridge the technological and cultural gap between technologists and conservators, and between managing authority (systems and techniques) and users of data and information (ICOMOS 2017); ii) actively contribute to the widespread exchange of best practices in the conservation process through debate and discussion in the scientific community, also in order to avoid duplication of efforts; iii) facilitate the standardization and simplification of procedures and tools; iv) develop methods and tools that are internationally recognized and applicable, in order to ensure accuracy, reliability and verifiability of the results.

\subsubsection{Teamwork}

The Cultural Heritage field is extraordinarily extended and presents a wide variety of possible professional applications, for this reason, it requires not only diversified and specialised professional figures, but especially people with an aptitude for teamwork and able to confront each other.

The necessary skills to work in $\mathrm{CH}$ field obviously concern the specific theoretical/technical skills, but it is also required to understand and interpret different languages (different professional figures) to accurately work in the field of conservation and enhancement of the cultural landscape entirety. 
It is therefore evident that the activity to be carried out on the "Cultural Heritage field" involves the intervention of many professional figures, the training of which is carried out through a series of course of

Furthermore, the management of Cultural Heritage involves a variety of participants, some of them public (Superintendencies, Local Authorities, Universities, Research Institutes), other individuals or associations of various kinds (Fig. 11). The summer school wants to actively contribute to the training of professionals who must be able to dialogue with each other and who can confront critically and constructively.
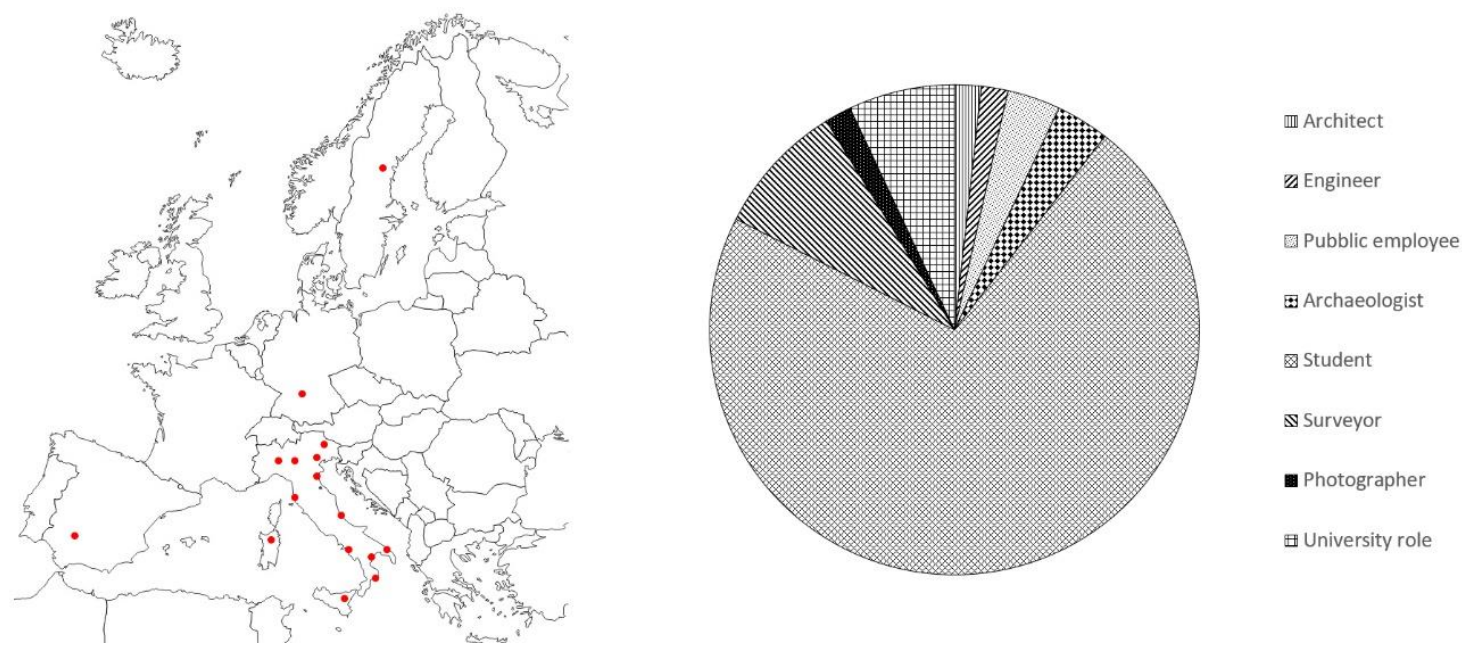

Fig. 12 participants' country of origin and occupation

In this meaning teamwork obliges to a continuous discussion; team speaks about times and ways to carry out the activities, and the different education and birthplace of the participants produce a constant exchange of opinions and counsels (Fig. 12). The course ends each year with the presentation of the results and a public discussion of the issues that have emerged. Participants should illustrate the methodological approach followed for field survey and subsequent data processing. The comparison and debate are particularly useful for those participants who come from "classical" survey experiences where the selection of significant information come first the conduct of field activities.
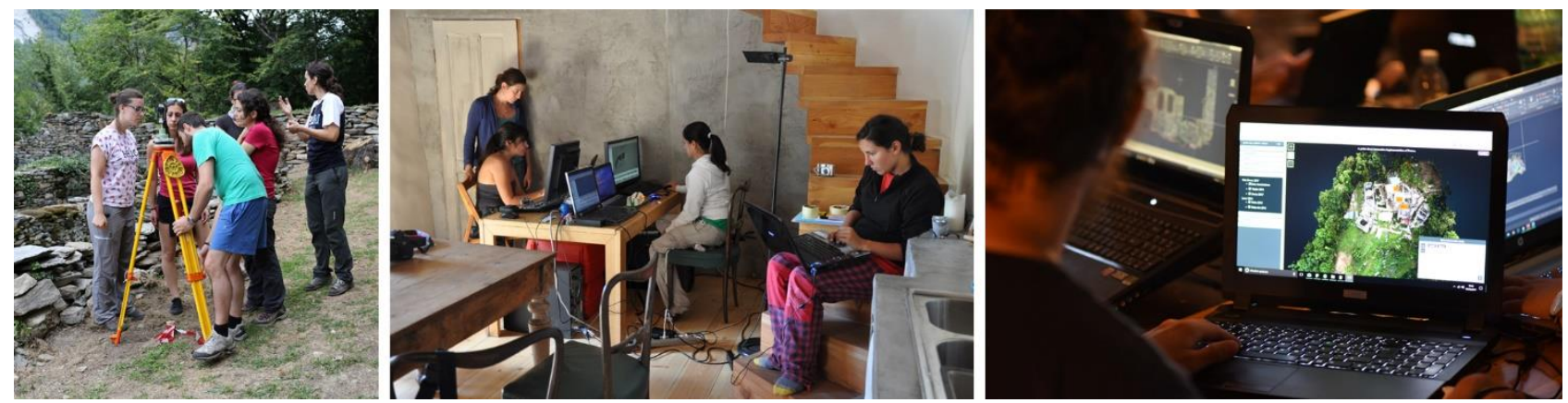

Fig. 13 Some team-working and discussion moments

The summer school employs modern survey techniques that reverse this practice by postponing the moment of interpretation/synthesis to the processing phase on the already acquired three-dimensional data. In this way, the different participant involved work at the same time on an "only one" 3D model that contains in itself all the information necessary for the various analyses. Therefore, the use of shared vocabularies and the ability to communicate data and reports from different specific sectors become indispensable.

\section{CONCLUSIONS}

The Italian Cultural, Artistic, and Environmental Heritage are ones of the widest of the world, and a lot of people think that they can be a progress launcher and an employment occasion. However, often both the 
political initiatives and even more the commercial ones focus on the emergencies/excellence. It is mandatory to re-evaluate the significant ad the role of the "minor" heritage instead, often neglected as essential identity element and as a building factor of the landscape and organisation of the territory. The possible actions should start from recognising this patrimony and its documentation, from the historical context but also the normative one, from the development of the knowledge. The aim is to reach the safeguard, the valorisation and the promotion activities, shared with the citizens, the Public Bodies and the financial and social operators (Italia Nostra 2017). Starting from this statement, the lifelong learning "Laboratory of Places" intent to transmit these values, through a multidisciplinary approach in the conservation process, maintaining a close collaboration with the local community. To do this, the mean of the school is the "objective" survey of the existing constructions, to represent the geometric shapes and quantities, to be aware of the materials' integrity and consistency, and to know the state of health of the buildings. In this way, the in-depth knowledge of the architectural aspects strengthens the local cultural values. In fact, the constant partnership with the Canova Association helps to the participants to live the territory, discovering local history and traditions. For this reason, the preservation in the case of Ossolano territory is a right balance between traditional and innovative cultures, knowledge, materials, and technologies, transmitting to the future generations the physical integrity of the built environment.

The positive feedback of each edition is due to the capability of the course to always present the latest methodologies and tools, showing a complete working method, useful both for the career and as a life experience.

\section{ACKNOWLEDGMENTS}

The authors wish to thank all the friends and colleagues who over the years have believed in "Ghesc project". The tutors of the different editions: Marta Caroselli, Maurizio Cesprini, Paola Gardin, Ken Marquardt, Paolo Volorio; students, who are passionate and always have enthusiastically participated in the activities; Kali, for the constant moral and logistical support; ICOMOS Italy and ISPRS for the sponsorship; Leica Geosystems in the person of Simone Oppici; Eng. Matteo Carocci of Open Technologies; Eng. Stefano Parri and Arch. Aldo Moia of NewThread, Luca e Marco Rosa Clot of Geostudio Rc.; and our colleague Cinzia Tommasi for the continuing support in proofreading.

\section{REFERENCES}

\section{Online Documents}

Associazione Italiana Biblioteche.

http://www.aib.it/, Accessed on 21/12/2017

Canova Association.

http://www.canovacanova.com/, Accessed on 07/12/2017

Centro Conservazione Restauro La Venaria Reale.

http://www.centrorestaurovenaria.it, Accessed on 21/12/2017

Centro Studi Orientamento. Guida alla formazione universitaria. http://www.cestor.it/atenei/guida.htm, Accessed on 28/10/2017

D.M. 270/04, Ministero dell'Università e della Ricerca. http://www.miur.it, Accessed on 21/12/2017

D.M 509/99, Ministero dell'Università e della Ricerca. http://www.miur.it, Accessed on 21/12/2017

Enciclopedia Treccani. http://www.treccani.it/enciclopedia/beni-culturali-e-ambientali/, Accessed on 04/01/2018

ISFOL Ente Pubblico di Ricerca sui Temi della Formazione delle Politiche Sociali e del Lavoro. 
http://www.isfol.it/, Accessed on 07/12/2017

Istituto per le Tecnologie Applicate ai Beni Culturali http://www.itabc.cnr.it/, Accessed on 07/12/2017

Italia Nostra, Settore Educazione al Patrimonio Culturale e Paesaggistico, Progetto per l'a.s. 2017-18. http://www.italianostra.org/?page_id=47, Accessed on 07/12/2017

Lavoro e Formazione.

https://www.lavoroeformazione.it/1/formazione/la-riforma-universitaria-dm-509-99,206, Accessed

Lifelong learning websites.

http://apps.unicatt.it/formazione_permanente, Accessed on 28/10/2017

http://www.centrostudilongobardi.it/eventi/index.html\#issue/corso_siti_unesco_2017/landscape/14, Accessed on 28/10/2017

http://www.unibo.it/it/didattica/corsi-di-alta-formazione/2017-2018\#!, Accessed on 28/10/2017 http://www.sitech-3dsurvey.polimi.it/?page_id=1759, Accessed on 28/10/2017

Master in Cultural Heritage websites.

http://www.bs.ilsole24ore.com/aree-tematiche/arte-cultura-e-design.html, Accessed on 06/11/2017 http://www.unive.it/pag/4971/, Accessed on 06/11/2017

https://www.masterin.it/masters/beni-culturali/, Accessed on 06/11/2017

http://www.culturedelpatrimonio.it/, Accessed on 06/11/2017

https://www.dssbc.unisi.it/it/didattica/master, Accessed on 06/11/2017

http://www.geomaticaeconservazione.it/aria_vpag.php?id_pagina=314, Accessed on 06/11/2017

http://www.geotecnologie.unisi.it/corsinew.php?act=tem\&id=4, Accessed on 06/11/2017

https://www.unimib.it/didattica/master-universitari/master-attivati-aa201617-corso/management-evalorizzazione-dei-beni-culturali, Accessed on 06/11/2017

http://www.unicatt.it/i-master-per-aree-tematiche-umanistica-e-beni-culturali, Accessed on 06/11/2017 http://www.unife.it/studenti/pfm/allegati/master/2017_18 - Master II Livello, Accessed on 06/11/2017 https://www.dssbc.unisi.it/it/didattica/master, Accessed on 06/11/2017 http://www.unicz.it/altaformanager/, Accessed on 06/11/2017

Opificio delle Pietre Dure.

http://www.opificiodellepietredure.it, Accessed on 06/11/2017

$\mathrm{PhD}$ Programs in Cultural Heritage.

http://www.beniculturali.unipd.it/www/corsi/dottorati-di-ricerca/presentazione/, Accessed on 28/10/2017 Corso di Dottorato in storia, critica e conservazione dei beni culturali, Accessed on 28/10/2017

http://www.beniculturali.unibo.it/it/attivita-didattica/dottorato-di-ricerca-in-studi-sul-patrimonio-culturale, Accessed on 28/10/2017

https://www2.almalaurea.it/cgi-asp/lau/postlaurea/dettaglioCorso.aspx?ID=44369\&lang=it, Accessed on $28 / 10 / 2017$

http://iuss.unife.it/corsi-di-dottorato/egus/sci-tecn-arch-beni-cult/sci-tecn-arch-beni-cult, Accessed on 28/10/2017

http://www.letterebeniculturali.unibo.it/it/corsi/corsi, Accessed on 28/10/2017

http://www.cnr.it/istituti/Istituto_DottRic.html?cds=026, Accessed on 28/10/2017

http://www.beniculturali.unipd.it/www/corsi/dottorati-di-ricerca/presentazione/, Accessed on 28/10/2017

Quaderni Di Ghesc Numero Zero - The Village Laboratory Ghesc un borgo per imparare. http://www.canovacanova.com/pubblicazioni, Accessed on 28/10/2017

SIRA Società Italiana per il Restauro dell'Architettura.

http://www.sira-restauroarchitettonico.it/it/scuole-di-specializzazione/, Accessed on 21/12/2017 
S.U.S.C.O.R. Struttura Universitaria in Scienze per la Conservazione, Restauro, Valorizzazione dei Beni Culturali.

http://conservazionerestauro.campusnet.unito.it/do/home.pl, Accessed on 04/01/2018

Università telematica Internazionale UniNettuno.

http://www.uninettunouniversity.net/it/descrizione-conservazione-e-valorizzazione-dei-beni-

culturali.aspx $?$ faculty $=5 \&$ degree $=239$, Accessed on 06/11/2017

Articles

Achille, C, Fassi, F., Lombardini, N., Gaudio, F., Galbusera, Survey of the archaeological site of Nemi. A training experience. Proceeding of XXIIIrd International CIPA Symposium, Prague, Czech Republic, September 12 - 16, 2011, ISBN 978-80-01-04885-6

Achille C, Fassi F, Marquardt K, Cesprini M (2017) Learning geomatics for restoration: ICOMOS summer school in Ossola Valley, The International Archives of the Photogrammetry, Remote Sensing and Spatial Information Sciences, Volume XLII-5/W1, 2017 GEOMATICS \& RESTORATION - Conservation of Cultural Heritage in the Digital Era, 22-24 May 2017, Florence, Italy, doi:10.5194/isprs-archives-XLII-5W1-631-2017

Fassi F, Mandelli A, Teruggi S, Rechichi F, Fiorillo F, Achille C (2016) VR for Cultural Heritage. A VRWEB-BIM for the future maintenance of Milan's Cathedral, Augmented Reality, Virtual Reality, and Computer Graphics- Contributo in Volume - ISBN:978-3-319-40650-3,978-3-319-40651-0

Rechichi F, Mandelli A, Achille C, Fassi F(2016) Sharing high-resolution models and information on web: The web module of bim3dsg system, ISPRS - International Archives of the Photogrammetry, Remote Sensing and Spatial Information Sciences - ISPRS Archives Volume 41, 2016 - DOI:10.5194/isprsarchivesXLI-B5-703-2016

ICOMOS (2014): Dichiarazione di Firenze Heritage and Landscape as Human Values (2014) Dichiarazione di principi e le raccomandazioni circa il valore dell'Eredità Culturale1 e del Paesaggio per la costruzione di una Società di pace e democrazia

ICOMOS 2017 - Documentazione preparatoria per la riunione del Consiglio di Direzione Firenze, 13-15 ottobre 2017

ICOMOS-ISCS, Illustrated glossary on stone deterioration patterns Glossaire illustré sur les formes d'altération de la pierre, ICOMOS International Scientific Committee for Stone (ISCS) . Comité scientifique international "Pierre" de l'ICOMOS, ISBN : 978-2-918086-00-0 EAN : 9782918086000 Impression septembre 2008, Ateliers 30 Impression, Champigny/Marne, France, 2008

Remondino, F., 2011. Rilievo e modellazione 3D di siti e architetture complesse 3D surveying and modelling of complex architectural sites and heritage objects. Disegnarecon dicembre 2011, ISSN 1828-5961

UNI 11182 - Normativa Italiana - Beni culturali Materiali lapidei naturali ed artificiali Descrizione della forma di alterazione - Termini e definizioni, Cultural heritage Natural and artificial stone Description of the alteration - Terminology and definition - La norma indica la scelta e la definizione dei termini utili per indicare le differenti forme di alterazione e degradazione visibili ad occhio nudo. Aprile 2006

UNI Normal 1/80 NorMal -Normativa Manufatti Lapidei, "Beni Culturali - Materiali lapidei naturali e artificiali - Descrizione della forma di alterazione - Termini e difinizioni" 